\title{
La garantía política de la supremacía constitucional: el caso del decreto de emergencia económica
}

\author{
Luis Alejandro Silva Irarrázaval*
}

\begin{abstract}
RESUMEN
La garantía del principio de supremacía constitucional es compartida por órganos jurisdiccionales y órganos políticos. En este artículo se desarrolla un caso que ejemplifica la garantía política de la supremacía de la Constitución: el decreto de emergencia económica. Esta atribución exclusiva del Presidente de la República es propia de su función de gobierno y, por tanto, esencialmente politica. La naturaleza del control de su ejercicio, en correspondencia con dicha potestad, es también politica y descansa fundamentalmente en el Congreso Nacional.
\end{abstract}

Supremacía constitucional; gobierno; Presidente de la República

\section{Deciding about budgetary exceptions: A political defense of the supremacy of the Constitution}

\begin{abstract}
The supremacy of the Constitution is guaranteed both by the judiciary and the political branches. This paper develops an example of a political warrant of constitutional supremacy, that of budgetary exceptions through presidential order. This constitutional power belongs to the President only and obeys to the President's constitutional function -to govern the Nation. Thus, it is a power driven by political prudence -essentially, it is a political power. Correspondingly, it is for Congress and not the Judiciary to control the exercise of such power.
\end{abstract}

Supremacy of the Constitution; Governance; President of the Republic

* Licenciado en Derecho, Pontificia Universidad Católica de Chile. Doctor en Derecho, Universidad de los Andes, Chile. Profesor de Derecho Constitucional, Universidad de los Andes, Chile. Correo electrónico: 1silva@uandes.cl

Este artículo se enmarca en el proyecto Fondecyt Regular $N^{\circ} 1161334$. Agradezco a María Ignacia Amtmann, alumna tesista, a Gustavo Díaz, ayudante, y a los varios profesores que generosamente comentaron el borrador.

Artículo recibido el 5.1.2019 y aceptado para su publicación el 3.9.2019. 


\section{INTRODUCCIÓN}

$\mathrm{E}$ 1 significado del principio de supremacía constitucional es unívoco en la teoría, pero equívoco en la práctica. Nadie discute que todos los órganos del Estado deban sujetarse a la Constitución, pero en cambio sí hay diferencias acerca de cómo se garantiza esto. Aunque la idea de una garantía jurisdiccional como instancia última para defender la supremacía está bastante extendida, sería apresurado admitirla como indiscutible. Frente a ella es posible defender la existencia paralela de una garantía política de la Constitución. Esto es precisamente lo que se propone revisar este artículo, sosteniendo como hipótesis que el Poder Judicial es incompetente para controlar al Presidente de la República (PDR) en su decisión de dictar (u omitir) un decreto de emergencia económica (DEE).

El problema es que, por una parte, hay autores que afirman la sujeción integral del Ejecutivo al control judicial ${ }^{1}$. Otros, en cambio, defienden la existencia de ciertos actos excluidos de dicho control ${ }^{2}$. En armonía con la primera posición, puede decirse que el Poder Judicial es el intérprete final de la Constitución. En consistencia con la segunda, puede afirmarse que hay un garante político de la supremacía constitucional. En el marco de esta discusión, es admisible preguntarse si la decisión de dictar un DEE representa uno de esos casos de garantía política de la supremacía constitucional. En definitiva, ¿podrá afirmarse que la decisión presidencial de dictar un DEE es un acto inmune al control judicial y, con ello, afirmar que la supremacía constitucional tiene también un garante político?

La tesis que se sostiene en este trabajo es de lege lata y consiste en afirmar que la decisión de dictar un DEE es, al menos en sus elementos discrecionales, inmune al control judicial y, por tanto, prueba de que la supremacía constitucional admite también una garantía política. Ello, porque la atribución del artículo $32 \mathrm{~N}^{\mathrm{o}} 20$ de la Constitución corresponde a uno de esos casos en que la ausencia de control judicial es una condición para garantizar el mejor ejercicio de la función. De hecho, el diseño institucional refleja esta circunstancia, lo que implica, finalmente, que la interpretación del texto de la Constitución (artículo $32 \mathrm{~N}^{\circ} 20$ ) está entregada a los órganos titulares del poder político: PDR y Congreso. En otras palabras, que la garantía de la supremacía constitucional es política ${ }^{3}$.

Algunas aclaraciones para precisar el marco de esta investigación. En primer lugar, nos enfocamos en el control del acto DEE y no en el control de su ejecución (cosa que admitimos). Segundo, y en consistencia con lo anterior: el caso central lo constituye el PDR y la pregunta de investigación es si el DEE es un acto susceptible de control judicial

${ }^{1}$ Paradigmático es el caso de Soto KLoss, quien ha defendido esta tesis con vigor y constancia a lo largo de muchos años, con amplia influencia. Dentro de su vasta obra, sugiero Soтo KLOss, 1996, pp. 31-43, especialmente pp. 39-40.

${ }^{2}$ Ver más adelante notas 43 y 63.

${ }^{3}$ Como se verá en la sección V, esta conclusión es compatible con admitir el control de CGR y del TC. Por otra parte, el planteamiento tiene precedentes. Ver Silva, 2018. 
y en qué medida. Por tanto, no hay un cuestionamiento in genere al control jurídico, del que el judicial es una especie, porque reconocemos la competencia de Contraloría General de la República (CGR) y, eventualmente, del Tribunal Constitucional (TC) ${ }^{4}$. Tercero: la cuestión versa sustancialmente respecto de la dimensión contencioso-objetiva del control, es decir, la sanción del DEE, y no acerca de la responsabilidad jurídica del PDR, que sería la dimensión contencioso-subjetiva.

El artículo está dividido en cuatro partes, además de la Introducción y la Conclusión. En la primera se plantea el problema del control judicial de los DEE, con el propósito de iluminar la tensión subyacente y lo que está en juego. La segunda parte busca presentar el DEE como un acto propio de las funciones de gobierno y, por tanto, con un margen de discrecionalidad más amplio que las administrativas. En la tercera se analiza con cierto detalle el DEE, con el objeto de justificar por qué este específico acto de la función gubernativa estaría exento del control judicial. La última parte presenta los argumentos que muestran la preponderancia de los órganos políticos en el control de la potestad presidencial y su acto correspondiente, el DEE.

\section{Planteamiento del problema}

La Constitución establece, como una de las atribuciones especiales del PDR, que este podrá, "con la firma de todos los Ministros de Estado, (...) decretar pagos no autorizados por ley, para atender necesidades impostergables derivadas de calamidades públicas, de agresión exterior, de conmoción interna, de grave daño o peligro para la seguridad nacional o del agotamiento de los recursos destinados a mantener servicios que no puedan paralizarse sin serio perjuicio para el país" (artículo $\left.32 \mathrm{~N}^{\circ} 20\right)^{5}$. En relación con esta potestad se plantea la problemática cuestión de su control judicial. Problemática, porque negar el control equivale para muchos a la creación de espacios de poder inmune al Derecho, cuestión inconciliable con el Estado de Derecho ${ }^{6}$. Pero problemática también porque aceptar dicho control supone algo así como situar a los jueces en la posición de árbitros de la política, resultado incompatible con la separación de funciones dentro del Estado moderno.

La discusión acerca del control judicial del DEE se enmarca en el debate más amplio respecto del control del poder político; del Ejecutivo, en este caso específico. Este debate puede formularse en la pregunta: ¿qué significa que el PDR esté sujeto a la Constitución? Pregunta que a su vez esconde otra que está en el núcleo del problema:

\footnotetext{
${ }^{4}$ En este trabajo se asume que el TC no ejerce un control judicial, porque no es parte del Poder Judicial, pero sí un control jurisdiccional. Esta distinción es controvertida. Por ejemplo, CEA, 2000, pp. 171-173, la afirma y BORDALí, 2002, pp. 34-52, la rechaza.

${ }^{5}$ Hasta la reforma constitucional de 2005 (Ley 20.050), esta atribución estaba en el numeral 22.

${ }^{6}$ Soto KLoss, 1996, p. 62: "O se desea que impere el derecho en una sociedad y, entonces, a los tribunales de la República se les erige en supremos guardianes de su imperio, o se admite que hayan sujetos (...) que sean inmunes al derecho”.
} 
¿cómo se garantiza la supremacía constitucional? Una respuesta rápida y extendida contesta que son los jueces, en definitiva, quienes aseguran la primacía de la Constitución, porque la Constitución es norma jurídica y son los jueces quienes dicen lo que el Derecho es. Sin embargo, esta contestación acarrea serias objeciones ${ }^{7}$.

Desde el punto de vista de la finalidad del DEE, afirmar que los jueces pueden juzgar si el Ejecutivo actuó conforme a la Constitución o no, representa una amenaza para su eficaz desenvolvimiento. Las causales que justifican un DEE son amplias a propósito, para dar al Ejecutivo el margen de maniobra que le permita responder a situaciones de bien común graves y urgentes. Puede decirse que el texto constitucional crea un espacio para la deliberación prudencial acerca de lo que conviene al buen gobierno frente a situaciones excepcionalmente graves. Someter este espacio de deliberación a las condiciones de un juicio judicial puede constreñirlo al punto de comprometer la eficacia del instrumento.

El control judicial de los DEE también representa un riesgo desde la perspectiva de la separación de las funciones estatales. Si el espacio creado por el artículo $32 \mathrm{~N}^{\circ} 20$, para el ejercicio de la prudencia política del gobernante, queda sujeto a la prudencia de los jueces, surge la posibilidad de que el razonamiento de los jueces discurra por una dimensión más política que jurídica. El significado específico de un supuesto como "necesidades impostergables" no está desarrollado en leyes ni reglamentos, sino que dependerá en cada caso del juicio prudencial del Ejecutivo. Autorizar a los jueces para juzgar la decisión de dictar o no un DEE agudiza severamente el problema de la sustitución de las funciones de gobierno mediante el control judicial ${ }^{8}$.

El anverso de la inmunidad judicial de los DEE es el peligro de abuso del poder político. Un Ejecutivo que gozara de la complicidad del Congreso (e incluso sin ella), podría disponer impunemente de enormes sumas de dinero para fines ajenos a los constitucionales. Y tolerar esta posibilidad, aún en pro de un gobierno eficaz o de conservar a los jueces alejados de la política, repugnaría con el Estado de Derecho.

Como se ve, la alternativa es problemática: si rehusamos el control judicial de los DEE, estamos abriendo la posibilidad de un abuso impune del poder político; pero si aceptamos el control, se estará comprometiendo el buen gobierno y judicializando la política. ¿Qué camino seguir?

\section{El DEE y LAS FUNCIONES DE GOBIERNO}

En esta sección se trata de señalar y caracterizar la relación existente entre el DEE y la función gubernativa, con el propósito de cimentar la defensa de la naturaleza eminentemente política de la atribución presidencial del artículo $32 \mathrm{~N}^{\circ} 20$.

${ }^{7}$ Silva, 2017, pp. 215-219.

8 Ver abajo nota 53. Sото, 1988, p. 126, critica esta objeción por estar apoyada en argumentos políticos “y enteramente inconsistentes racionalmente”. Queda sin explicar por qué la naturaleza política del argumento invalidaría la objeción; y, en cuanto a la inconsistencia racional, esta debe entenderse en el marco de su concepción del Estado de Derecho. 


\section{Las funciones de gobierno y de administración}

Decir que el DEE corresponde a una potestad exclusiva del PDR es insuficiente para justificar la inmunidad judicial del acto: las actuaciones del Ejecutivo sometidas a un efectivo control judicial son innumerables. Algo más es preciso para justificarlo, y ello es la distinción entre las funciones de gobierno y las de administración. Con base en este binomio, es posible introducir un criterio que permita explicar la inmunidad de ciertos actos del Ejecutivo -y del DEE, específicamente-: aquellos propios de la función de gobierno.

Esta distinción entre gobierno y administración es canónica en el Derecho Constitucional, aunque varíen sus expresiones institucionales: o bien titulares distintos para cada una de ellas -distinguiendo entre jefe de Estado y jefe de gobierno- o uno solo que las concentra a ambas ${ }^{9}$. En el caso chileno la Constitución optó por esta segunda forma. El artículo 24 inciso $1^{\circ}$ dice: "El gobierno y la administración del Estado corresponden al Presidente de la República, quien es el Jefe del Estado”.

\section{Las funciones de gobierno: una caracterización}

La función de gobierno reúne ciertas características que permiten entender por qué su ejercicio podría estar exento del control judicial ${ }^{10}$. Entre estas características, todas consistentes con la finalidad propia de la función gubernativa, destaca la discrecionalidad en el ejercicio del poder ${ }^{11}$. Esta discrecionalidad consiste en el margen que el titular del gobierno debe tener para ejercer con prudencia sus responsabilidades. En el caso del gobierno, el margen es más amplio que en el de la función administrativa, porque la naturaleza de las necesidades que le son propias es más difícil de satisfacer regladamente.

Desde la perspectiva de la discrecionalidad, la función de gobierno puede también llamarse política ${ }^{12}$. Y es que una nota peculiar de la política es la amplitud del ámbito que los titulares del poder político tienen para desenvolverse en el cumplimiento de sus tareas específicas. Esta cercanía conceptual entre gobierno y política permite entrever la relativa inmunidad que las funciones de gobierno pueden reclamar respecto del control judicial, que es esencialmente jurídico ${ }^{13}$.

${ }^{9}$ Gobierno y administración designan dos funciones distintas pero complementarias. La primera responde a la necesidad de dirección o guía de la colectividad política y la segunda procura la satisfacción de las necesidades públicas. Muñoz, 2017, pp. 133-134. En el mismo sentido, Aylwin y Azócar, 1996, p. 29.

${ }^{10}$ Aylwin y Azócar, 1996, p. 29, caracteriza la tarea de gobierno "por el móvil político que la inspira, por la importancia de las materias que afronta, por su carácter orientador, que se manifiesta en las decisiones de principios, y por el grado máximo de ejercicio del poder que entraña”.

${ }^{11}$ Cea, 2000, p. 167; Verdugo y García, 1998, p. 213.

${ }^{12}$ CEA, 2000, pp. 167, entiende la política como una subfunción del gobierno. Las otras dos subfunciones son la ejecutiva y la administrativa.

${ }^{13}$ En esta afirmación se está asumiendo la distinción entre los ámbitos jurídico y político, y la relativa autonomía que cada uno tiene respecto del otro. Admitir la autonomía de lo político respecto de lo jurídico supone la existencia de una definición de lo político. Aquí nos contentamos con una definición parcial y 
La discrecionalidad propia del gobierno no es absoluta ni debe confundirse con la arbitrariedad. Las funciones de gobierno, como todas las demás, están normativamente perfiladas por lo que se entiende que son las condiciones racionales para su ejercicio. Lo que sucede es que estas condiciones reconocen la necesidad de habilitar un espacio generoso "de creatividad y de libertad para mandar en atención al mérito de los hechos que [la misma autoridad] pondera prudencialmente" 14 .

Debido al grado de discrecionalidad que demanda su adecuada atención, hay una serie más o menos típica de materias que se entienden propias de las funciones de gobierno. Entre ellas es posible mencionar la seguridad interior y exterior del Estado, y las relaciones internacionales. Esta asociación entre materia y función puede extenderse a los medios necesarios para actuar. Por eso es que, también típicamente, se incluyen dentro de las funciones de gobierno los poderes para decretar un estado de excepción constitucional, declarar la guerra, nombrar a las más altas autoridades militares o a los representantes exteriores del Estado, entre otras. Por la misma razón, podría extenderse a la administración de la hacienda pública ${ }^{15}$.

\section{Acerca de la especial relación entre la bacienda pública y las funciones de gobierno}

La administración de la hacienda pública es un instrumento crítico para el gobierno, porque las decisiones normalmente requieren financiamiento para materializarse. Esta dependencia, que podríamos llamar funcional, tiene una confirmación histórica y se refleja dogmáticamente en el ordenamiento constitucional.

\section{a) La dependencia funcional}

El rango y la complejidad de las tareas a las que el gobierno debe hacer frente reclaman naturalmente un elevado grado de discrecionalidad en la administración de los recursos públicos ${ }^{16}$. De allí que, no obstante la necesidad de limitar la discrecionalidad para evitar los peligros asociados a su abuso, el marco normativo le garantice un espacio

básica: político es el ámbito en que lo justo se define de entre una variedad más o menos amplia de opciones indiferentes desde la perspectiva de la justicia hasta el momento de la decisión. Queremos referirnos a la determinación de lo justo legal, aquello que para ARIstóteles Nic. Eth. 1134b.20, originalmente resulta indiferente [desde la perspectiva de lo justo] que sea establecido de una manera o de otra, pero que habiendo sido establecido, deja de ser indiferente. De donde Tomás de Aquino Sententia Ethic., lib. 5 1. 12 n. 8; Summa Theologiae I-II q. 95 a. 2 enseña que lo justo legal puede ser obtenido de lo justo natural por determinación, es decir, mediante leyes cuya "fuerza obligatoria les viene (...) de la misma autoridad divina o humana que los determina como derecho vigente".

${ }^{14}$ CEA, 2000, p. 168.

15 Verdugo et al., 2002, p. 199. Molina, 2009, pp. 333-339. La del artículo $32 \mathrm{~N}^{\circ} 20$ se entiende como una atribución gubernativa de naturaleza financiera, GARCía y ConTreras, 2014, pp. 741-742.

16 Cordero, 2007, p. 163, reconoce este margen de discrecionalidad del PDR, como cabeza del Gobierno y la Administración, apoyándose expresamente en el criterio funcional. 
amplio. La articulación institucional entre el PDR y el Congreso en torno al gasto público proyecta precisamente esto ${ }^{17}$.

Los principios normativos que rigen acciones tan relevantes - desde la perspectiva de la hacienda pública- como la tributación (legalidad tributaria) y el gasto (legalidad del gasto público), han de conceder necesariamente un lugar al arbitrio de la autoridad encargada del gobierno, si es que no se quiere comprometer el bienestar social ${ }^{18}$. Cualquier arreglo debe considerar un equilibrio entre el ámbito de las atribuciones regladas y las discrecionales, a sabiendas de que el exceso en cualquier sentido puede resultar perjudicial para la buena marcha del Estado ${ }^{19}$.

El margen de discrecionalidad del gasto público es indispensable para el ejercicio adecuado de las funciones de gobierno ${ }^{20}$. Por cierto, esta exigencia viene marcada por determinadas situaciones que, desde la urgencia, demandan una reacción rápida de la autoridad, y precisamente es el Ejecutivo quien cuenta con el diseño institucional más apropiado para responder ante esas circunstancias. Pero también incide en esta relación entre gobierno y discrecionalidad, la relativa indiferencia que, desde el punto de vista de la justicia, tantas veces cubre el haz de opciones con que la autoridad puede elegir hacer frente a una necesidad determinada ${ }^{21}$.

\section{b) La confirmación histórica}

La intrínseca dependencia que el adecuado ejercicio del gobierno tiene respecto del manejo de la hacienda pública puede ilustrarse con la discusión parlamentaria de la ley de reforma constitucional 7.727, de 1943, que restringió la iniciativa del Congreso en materia de gasto público ${ }^{22}$.

Hasta el año de la reforma, el Congreso tenía la iniciativa para disponer gastos de la hacienda pública mediante la creación de nuevos servicios o empleos públicos, o el

\footnotetext{
${ }^{17}$ Pineda, 2000, pp. 373-374, indica la correlación entre la forma de la estructura política y el manejo de la hacienda pública en el marco de una determinada concepción del Estado de Derecho.

18 Tribunal Constitucional, 26. 4.1997, rol 254, en que un grupo de senadores demandó la inconstitucionalidad de un decreto supremo que establecía normas acerca de modificaciones presupuestarias para el año siguiente, porque en la práctica estaría permitiendo efectuar gastos no aprobados por ley. El TC rechazó el requerimiento, argumentando que, para la ejecución del presupuesto, las potestades del PDR "deberían contar con la flexibilidad necesaria para que no pierdan el sentido que la Constitución señala para tan importante materia en el desarrollo integral del Estado” (cons. $2^{\circ}$ ). Ver también considerandos $16^{\circ}$ y $18^{\circ}$.

19 Pineda, 2000, pp. 375-377.

${ }^{20}$ Molina, 2009, p. 334.

${ }^{21}$ Soto KLoss, 2009, p. 362, define la discrecionalidad como "la libertad de apreciación para decidir, frente a determinados hechos objetivos - que la ley ha descrito o previsto como necesidad pública- la adopción de la mejor medida a fin de satisfacer eficiente y oportunamente dicha necesidad". Poco más adelante, sin embargo, precisa que de todas las posibilidades contenidas en ese rango de discrecionalidad "solo una es la idónea en el caso concreto", y apoya su aserto en una imagen geométrica. Como si la tarea de gobernar pudiera compararse con un plano matemático, Soto KLoss, 2009, p. 364 y el ejemplo en nota 17.

${ }^{22}$ La misma reforma constitucional creó el decreto de emergencia económica, dio estatus constitucional a la CGR e incluyó al Contralor General entre los sujetos pasivos de una acusación constitucional.
} 
aumento de sueldo o gratificaciones pecuniarias a los empleados de la Administración Pública. El uso inmoderado de esta competencia tenía por contrapartida al PDR administrando los dineros públicos al margen de la ley, vía decretos de insistencia. El ejercicio paralelo de estas potestades carentes de control mutuo estaba conduciendo a la quiebra económica del país ${ }^{23}$.

La reforma que se discutió consistía, esencialmente, en concentrar la iniciativa del gasto público en el PDR. El entonces ministro de Justicia, Oscar Gajardo, cuando defendió el proyecto ante la Cámara de Diputados, dijo: "Si el factor económico es determinante para el éxito de un gobierno y por lo tanto para la felicidad de la ciudadanía, la marcha de las finanzas solo podrá ser acertada cuando su dirección esté en una sola mano” ${ }^{24}$. La necesidad de una simetría entre la responsabilidad y la potestad del PDR en relación con el manejo de la hacienda pública fue clave en el debate ${ }^{25}$.

\section{c) La dogmática constitucional}

El ordenamiento jurídico recoge y proyecta la relación instrumental que existe entre la hacienda pública y las funciones de gobierno. Como ya se ha insinuado, la tensión inherente a la discrecionalidad en el manejo de los fondos fiscales reclama un conjunto de mecanismos que limiten el ejercicio del poder ejecutivo en la materia. Pero estas limitaciones necesarias sirven como evidencia de que la potestad está esencialmente radicada en el Ejecutivo.

Quizá la norma constitucional más elocuente sea el artículo 65 de la Constitución. $\mathrm{Su}$ inciso $3^{\circ} \mathrm{y}$, especialmente, los numerales 1 al 4 del inciso $4^{\circ}$, manifiestan de modo inequívoco la decisión de alojar las iniciativas que impliquen gastos en el Poder Ejecutivo. Aunque la obligación de encauzarlas por medio del Congreso suponga para el PDR una limitación importante, tener la iniciativa le confiere un margen de discrecionalidad amplísimo, frente al reducido número de posibilidades que tiene el Congreso, que son “aceptar, disminuir o rechazar" las propuestas presidenciales.

Un segundo ejemplo es el artículo 67, que reserva la presentación del proyecto de Ley de Presupuesto al PDR, dándole exclusividad para estimar el rendimiento de los recursos de la Ley de Presupuesto y potestad para disminuir los nuevos gastos aprobados por el Congreso en proporción a los ingresos que deberían financiarlos. Aun cuando el poder del Congreso para influir en el Ejecutivo sea de hecho harto mayor que lo que esta norma permitiría pensar, lo cierto es que ella refleja la decisión de responsabilizar al PDR en la ejecución del presupuesto nacional y del gasto público en general.

23 Bien lo resumió el diputado Jorge Urzúa durante la discusión de la reforma, Diario de Sesiones, Cámara de Diputados, $45^{\text {a }}$ sesión ordinaria, p. 1885.

${ }^{24}$ Diario de Sesiones, Cámara de Diputados, 1943, 6a sesión ordinaria, p. 1012.

${ }^{25}$ Por ejemplo, Diario de Sesiones, Cámara de Diputados, 1943, 44 a sesión ordinaria, pp. 1836, 1840, 1843; $45^{a}$ sesión ordinaria, p. 1877; 48 sesión ordinaria, p. 1946. 


\section{Gobierno, bacienda y emergencia}

Hemos enfatizado lo natural que resulta confiar el manejo de la hacienda pública -con todas las restricciones del caso- a la autoridad de gobierno, porque para el adecuado cumplimiento de las funciones que le son propias dos elementos resultan indispensables: discrecionalidad y disponibilidad de recursos monetarios. Los factores que conducen a este resultado no son contingentes, sino que forman parte de la estructura misma del Poder Ejecutivo, desde una perspectiva finalista. Esta configuración estructural del gobierno se hace aún más clara bajo la influencia de una circunstancia que sí es contingente: la urgencia.

Si es cierto que en condiciones normales la atención a las necesidades de la población demanda del gobierno una articulación ágil entre discrecionalidad y capacidad de gasto, en circunstancias extraordinarias que reclaman una respuesta urgente, esta articulación resulta más que justificada. La Constitución reconoce esta estructura y es sensible al grado en que la urgencia exige despojarla de formalidades para aumentar su eficacia. De allí que, por ejemplo, para financiar gastos imprevistos en circunstancias de normalidad, el Ejecutivo tenga la iniciativa exclusiva, pero deba tramitarse como ley (artículo $65 \mathrm{~N}^{\circ}$ 3); en cambio, en un escenario de emergencia, el PDR pueda financiar gastos imprevistos mediante un decreto firmado por todos sus ministros.

Las causales constitucionales para que opere el DEE representan una versión extrema de la dinámica que articula la tríada gobierno, discrecionalidad y hacienda pública. La existencia de "necesidades impostergables", creadas por circunstancias de particular gravedad, intensifica el efecto de las premisas que sostienen la relación estructural entre las funciones de gobierno y la responsabilidad del gasto público ${ }^{26}$.

\section{El DEE Y EL CONTROL JUDiCiAL}

La prerrogativa estipulada en el artículo $32 \mathrm{~N}^{\circ} 20$ de la Constitución define un marco de apreciación para que el PDR decida gastar fondos públicos no previstos en la ley. La pregunta que atraviesa este trabajo es si la decisión que resulta de dicha ponderación, materializada en el DEE, puede ser impugnada en sede judicial. En esta sección se analiza el estatuto constitucional del DEE y las distintas tesis que se han dado para explicarlo, para concluir que su diseño responde a esa clase de actos que es mejor excluir del control de los jueces.

${ }^{26}$ Si desde la perspectiva del principio de legalidad del gasto público esta atribución especial constituye una excepción, desde el punto de vista de la relación entre gobierno y hacienda pública, no hace más que confirmarla. 


\section{El estatuto constitucional del DEE}

Los distintos elementos del estatuto constitucional del DEE permiten inferir que la atribución presidencial es propia de la función de gobierno, cuyos actos estarían (o debieran estar) exentos de control judicial.

\section{a) La firma de todos los ministros}

Este requisito formal es el mismo que se exige para los decretos de insistencia (artículo 99 de la Constitución). La coincidencia no es casual. Es preciso recordar que el DEE se configuró como una atribución presidencial específica precisamente para poner fin al abuso de los decretos de insistencia, que era la vía para obtener recursos no contemplados en la ley ${ }^{27}$. Este antecedente es importante, por el significado que tiene la relación entre el requisito de la firma y la insistencia. El mecanismo de la insistencia obedece, en el fondo, a la responsabilidad última que tiene el PDR sobre el gobierno y la administración del Estado, y es la forma en que se le reconoce la decisión final en materias de su incumbencia ${ }^{28}$. La firma de todos los ministros es una forma simbólica de refrendar la voluntad política que insiste en dar curso a una decisión objetada en su legalidad ${ }^{29}$.

\section{b) Las causales}

En este punto, dos son los motivos que invitan a concluir el carácter político no justiciable del DEE: la amplitud de las causales y su semejanza con otra institución de orden político.

La amplitud de las causales. El supuesto de hecho que habilita al PDR para decretar pagos no autorizados por la ley es una estructura compuesta por dos partes. La primera consiste en las circunstancias fácticas que alteran, o amenazan con alterar, el statu quo, y que pueden ser calificadas de diversas maneras (calamidad pública, agresión exterior, etc.). La segunda consiste en los efectos que se derivan de dichas circunstancias y que deben ser calificados como "necesidades impostergables". Una y otra corresponden a conceptos jurídicos indeterminados. Estos conceptos habilitan al intérprete un amplio espacio de maniobra que, de ordinario, es necesario para que la norma que los contempla

${ }^{27}$ Ver la moción del senador Maza que dio inicio a la tramitación de la reforma constitucional, Diario de Sesiones, Senado, 1942, Sesión 14 a ordinaria, pp. 568-569.

${ }^{28}$ Pallavicini, 2010, p. 126. CGR, 8.8.1952, N 30.692, así lo dijo: "A la circunstancia de que prima la voluntad del Ejecutivo, obedece precisamente la exigencia impuesta por el Constituyente de que estos decretos requieran la firma de todos los Ministros de Estado”.

29 "Tal exigencia compromete políticamente al Presidente y sus Ministros, en el evento de una acusación constitucional”, García y Contreras, 2014, p. 261. El mecanismo para contrapesar esta facultad del Ejecutivo confirma el cariz político de la intención que motiva la insistencia: debe enviarse copia de los decretos a la Cámara de Diputados. ¿Por qué a la Cámara de Diputados? Porque en ella reside la facultad de fiscalizar los actos del gobierno, una facultad de naturaleza política. 
sea útil. Las causales del DEE son funcionales a la finalidad que el DEE está llamado a cumplir ${ }^{30}$. En esta tarea, las consideraciones de conveniencia y oportunidad le son esenciales $^{31}$. El control jurídico sobre estos elementos debería limitarse a verificar el cumplimiento de las formas legales (elementos reglados del acto); ir más allá fácilmente se transforma en una superposición de funciones ${ }^{32}$.

La semejanza con otra institución de orden político. Los términos escogidos para las causales del DEE son, en varios casos, idénticos a los utilizados en el estatuto constitucional de los estados de excepción. Es el caso de calamidad pública (artículos 39 y 41), conmoción interna (artículos 39 y 41) y grave daño para la seguridad de la nación (artículo 42). El caso de agresión exterior es equivalente al de guerra exterior (artículo $40)^{33}$. Esta correspondencia entre las causales del DEE y de los estados de excepción constitucional es sugerente en el marco de nuestra hipótesis, porque la declaración de los estados de excepción constitucional es una atribución política que, en principio, no está sujeta al control judicial ${ }^{34}$. Por analogía, podría uno concluir que el DEE, como el decreto que declara un estado de excepción constitucional, es un acto judicialmente inimpugnable.

\section{c) La irresponsabilidad jurídica del PDR}

La última parte del artículo 32 N 20 dice: "Los Ministros de Estado o funcionarios que autoricen o den curso a gastos que contravengan lo dispuesto en este número serán responsables solidaria y personalmente de su reintegro, y culpables del delito de malversación de caudales públicos”. En el entendido que se trata de una responsabilidad jurídica, la omisión del PDR en esta disposición es significativa. ¿Por qué razón esta diferencia de trato entre el PDR, por una parte, y todos sus Ministros y demás funcionarios, por otra? ${ }^{35}$ ¿Por qué el PDR es jurídicamente irresponsable por contravenir el

${ }^{30}$ Este margen de libre apreciación del PDR para hacer frente a las necesidades impostergables del país, fue ampliado por la Constitución al eliminar el adverbio "sólo" que contenía el artículo 72 N $^{\circ} 10$ de la Constitución de 1925, SiLva, 2000, tomo V, p. 260.

${ }^{31}$ Es lo que entendió CGR, 8.8.1952, No 30.692: "[La causal necesidades impostergables] corresponde indudablemente a una apreciación de hecho que dentro de nuestro régimen jurídico debe calificar íntegramente el Poder Ejecutivo puesto que sólo al Presidente de la República en su carácter de Supremo Administrador del Estado compete la calificación de la conveniencia y oportunidad de los actos de administración”.

${ }^{32}$ Es jurisprudencia establecida de CGR que esta no realiza un control de mérito -conveniencia y oportunidad-sino de legalidad. Por todos, CGR, 1.8.2006, No 35.617. En su oportunidad, Guzmán explicó que no es función de Contraloría calificar si han concurrido las causales del DEE, "porque se trata de una apreciación netamente política”, Actas Comisión de Estudios de la Nueva Constitución (CENC), sesión $326^{a}$.

${ }^{33}$ La única causal que no tiene correspondencia con las de los estados de excepción constitucional es la del agotamiento de los recursos que afecten servicios esenciales para el país.

${ }^{34}$ Decimos "en principio" porque, tras la reforma constitucional de 2005, el artículo 45 inciso $1^{\circ}$ abrió un espacio para el control. No obstante, la Corte Suprema, 24.12 2013, rol 4029-2013, ignoró esta disposición y afirmó que la potestad del PDR es inmune al control judicial, SiLva, 2018, pp. 82-84 y 99-100.

35 Diferencia, por lo demás, que replica la establecida como regla general en el artículo 36 de la Constitución. 
artículo $32 \mathrm{~N}^{\mathrm{o}} 20 ?^{36} \mathrm{El}$ punto adquiere mayor hondura si consideramos que el artículo $53 \mathrm{~N}^{\circ} 2$ de la Constitución solo se refiere a los ministros como legitimados pasivos de acciones judiciales intentadas por particulares. De nuevo, ¿por qué esta distinción tan marcada entre el PDR y sus ministros respecto de la responsabilidad jurídica?

Parece que lo más razonable es entender que se trata de una disposición característica del régimen presidencial chileno, que debe leerse como la indispensable proyección de la exigencia planteada por el carácter irreductiblemente político de su potestad ${ }^{37}$. En este sentido, sería incorrecto pensar que esa irresponsabilidad constituye una excepción al principio general de responsabilidad de la Administración: la actuación del PDR no es de carácter administrativo sino político ${ }^{38}$.

\section{Acerca de la naturaleza del DEE}

La impunidad judicial del DEE, obliga a plantearse la cuestión acerca de la naturaleza del acto: ¿qué es el DEE para el Derecho? El interés de la respuesta no es uno de carácter especulativo para la ciencia del Derecho Público, sino práctico (¿puede perseguirse el DEE judicialmente?) y técnico (¿cuáles son los argumentos?).

\section{a) Decreto reglamentario autónomo}

El reconocimiento constitucional de la potestad reglamentaria autónoma creó un espacio de regulación exclusivo del PDR. Su fundamento estaría en la necesidad de dotar a las autoridades de gobierno de los instrumentos adecuados para conducir la vida nacional ${ }^{39}$. Haciendo una analogía con el principio de reserva legal, la potestad reglamentaria autónoma podría llevarnos a hablar de una reserva de gobierno, que nos presentaría al PDR como "un ente autónomo y con legitimidad propia, que extiende

${ }^{36}$ CEA, 2012, tomo III, p. 152, entiende que el PDR está comprendido en la categoría "funcionarios". Aparte de que no ofrece argumento alguno, esta interpretación mal se condice con la mención expresa a los ministros, porque sugiere que estos son más importantes que el PDR.

37 Sería una de las trazas del régimen portaliano, Edwards, 1928, p. 295; Harriet 1963, p. 135. La caracterización del PDR como un "pequeño monarca temporal, absoluto e irresponsable" (Gabriel Amunátegui, citado por HARriet, 1963, p. 308) invita a pensar en el axioma constitucional del Derecho inglés The King can do no wrong, que significa -entre otras cosas- que los ministros responden por los actos del monarca, Blackstone Tomo I, p. 245 y Tomo III, pp. 254-255. No es, entonces, casualidad que ZúÑIGA, 2006, califique la irresponsabilidad civil del PDR por los decretos que firma, como "un verdadero resabio monárquico" (la firma de los ministros transferiría la responsabilidad civil hacia ellos, eximiendo al PDR).

${ }^{38}$ CALDERA, 1991, pp. 212-213, partiendo justamente de esta premisa que criticamos, distingue entre la responsabilidad directa o inmediata de los ministros, y la responsabilidad global (o indirecta) del PDR. No ofrece, sin embargo, ninguna explicación del porqué del estatuto especial del PDR.

39 Así, Guzmán, CENC, sesión 355a: "[recalcó] la congruencia que existe entre este criterio [que distingue entre potestad reglamentaria de ejecución y autónoma, defendido por Bertelsen] y la concepción del Gobierno moderno en cuanto ser el conducto de la vida nacional, especialmente en los planos económicos, administrativo, internacional y social" (que se corresponde con la potestad reglamentaria autónoma, por supuesto). También Argandoña, 1981, p. 224, aunque lo critica. 
su autoridad de dirección política - de acuerdo con la Constitución y las leyes- a todo cuanto tiene por objeto la conservación de los intereses nacionales" 40 .

Este ámbito de competencia está, en principio, demarcado únicamente por la Constitución y de manera negativa: cae dentro de él todo lo que no sea materia propia de $l e y^{41}$. Las decisiones que se adopten en este ámbito prescinden de toda habilitación legal, porque se apoyan directamente en la Constitución. Aunque la facultad de dictar un DEE se ejerce por definición al margen de la ley y se apoya inmediatamente en la Constitución, podría postularse que el DEE es un acto propio de la potestad reglamentaria autónoma.

El control de los actos que resultan del ejercicio de la potestad reglamentaria autónoma es controvertido. Porque si el acto reglamentario autónomo es igualado al acto reglamentario de ejecución, entonces se le aplican los mismos criterios que corren para el control de estos. Es decir, los jueces serían competentes para enjuiciarlos ${ }^{42}$. En cambio, si se entiende que son actos de gobierno -o que al menos algunos de ellos pueden serlo-, entonces no cabría su control judicial ${ }^{43}$.

\section{b) Decreto con Fuerza de Ley}

La idea de que el DEE es un Decreto con Fuerza de Ley (DFL) es una tesis del profesor Molina ${ }^{44}$. Él llega a esta conclusión a partir del artículo 89 de la Constitución, que dice: "Las Tesorerías del Estado no podrán efectuar ningún pago sino en virtud de un decreto o resolución expedido por autoridad competente, en que se exprese la ley o la parte del presupuesto que autorice aquel gasto". De las dos condiciones alternativas enunciadas, debe descartarse de plano aquella que exige expresar "la parte del presupuesto que autorice aquel gasto" porque, por definición, el DEE dispone de fondos no presupuestados. Así entonces, habría de entenderse que el DEE hace las veces de ley, y los decretos o resoluciones de gastos contra el $2 \%$ constitucional deberán remitirse al DEE como la ley que autoriza el gasto.

Debido a que el DEE sirve como la ley que autoriza los gastos, sin ser ley propiamente hablando; y ya que no puede ser un decreto, porque entonces fallaría la condición exigida por el artículo 89, se deduce que el DEE es un DFL. Molina avala esta conclusión con un argumento de Derecho Comparado, con el que quiere señalar el siguiente patrón:

40 Cazor y Pfeffer, 2009, pp. 196-197.

${ }^{41}$ Esta definición debe entenderse complementada por el principio de que en Derecho Público solo puede hacerse aquello que está permitido.

42 Esta es la posición de quienes miran como equivalentes ambas formas de ejercicio del poder reglamentario: Aylwin, 1984, p. 450; Argandoña, 1981, p. 217; CEA, 2012, p. 150.

43 ZÚÑIGA, 2001, p. 54, afirma que los actos de la potestad reglamentaria autónoma, así como los actos de gobierno, están excluidos del control judicial, al menos vía recurso de protección.

${ }^{44}$ Molina, 2001a, p. 101. La misma tesis en: Molina, 2000; Molina, 2001b; Molina, 2009, pp. 337-339. 
las situaciones de emergencia nacional se enfrentan por el Ejecutivo con disposiciones que tienen fuerza de ley ${ }^{45}$.

En la hipótesis que estamos analizando, el control de los DEE sería el propio de los DFL. En consecuencia, solo CGR (artículos 64 inciso $6^{\circ}$ y 99 inciso $2^{\circ}$ ) y el TC (artículo $93 \mathrm{~N}^{\text {os }} 4,6$ y 7) serían competentes para controlarlos ${ }^{46}$. Ante la posibilidad de un control judicial de los DFL, habría que estarse a la doctrina respecto de la responsabilidad del legislador, que en la actualidad es apenas admitida fuera de los casos propios del control de constitucionalidad, y que contaría con mínima jurisprudencia de respaldo ${ }^{47}$.

\section{c) Decreto supremo de ejecución}

El DEE puede también entenderse como un decreto supremo de ejecución, que es la vía jurídica formal ordinaria por la que el PDR ejerce sus potestades ${ }^{48}$. En principio, esta clase de actos está sujeta al control judicial sin más limitaciones que las procedimentales ${ }^{49}$. Lo normal es que el control consista en verificar la legalidad del decreto, pero por la vía del recurso de protección se podría cuestionar indirectamente su constitucionalidad. Nada obstaría, entonces, a que un tribunal de justicia juzgara la validez de un DEE, desde la perspectiva de su marco habilitante (que en este caso sería el artículo $32 \mathrm{~N}^{\circ} 20$ de la Constitución) o desde la perspectiva de las garantías constitucionales amparadas por el recurso de protección.

\section{Discrecionalidad, deferencia y actos de gobierno}

Si se quiere entender el DEE como un acto administrativo -en cuanto es un acto sujeto al control judicial- es preciso invocar la diferencia entre elementos reglados y elementos discrecionales del acto ${ }^{50}$. Serían reglados los siguientes: la firma de todos los ministros y el 2\% del presupuesto de la Nación como límite del total de los gastos. Discrecionales serían, en cambio, la calificación de las necesidades (finalidad) y de los hechos que las causan (motivos), así como la forma de enfrentarlas ${ }^{51}$. La diferencia entre

45 Molina, 2001, pp. 101-102. Los ejemplos los toma del Derecho español, francés e italiano.

${ }^{46}$ Con la peculiaridad de que la "ley habilitante" sería la misma Constitución; una característica, por lo demás, que sería típica de los actos de gobierno, Aguilar, 2005, pp. 528-534; Ríos, 1975, pp. $413-414$.

${ }^{47}$ Barros, 2010, pp. 520-522. Durante los primeros años del recurso de protección, se postuló que también el legislador era legitimado pasivo de esta acción procesal: Soто KLoss, 1982, pp. 321-322. Pero hoy no conocemos a nadie que lo sostenga.

${ }^{48}$ Artículo 3 inciso $4^{\circ}$, Ley 19.880. Moraga, 2010, pp. 122-123 lo caracteriza como un tipo especial de decreto supremo.

49 Artículo 15 inciso $2^{\circ}$, Ley 19.880 (principio de impugnabilidad de los actos administrativos).

50 Esta distinción es una analogía de aquella entre las potestades de la administración, regladas y discrecionales, Moraga, 2010, pp. 33-36.

${ }^{51}$ Entendemos que esta clasificación podría discutirse, porque, por ejemplo, alguno podría entender que la finalidad y la motivación del acto son elementos reglados, Soто KLOss, 2009, p. 363. Estaríamos dispuestos a abandonar esta clasificación si, en cambio, se nos concediera que son conceptos jurídicos indeterminados 
estas categorías de elementos sirve para justificar una limitación al alcance del control judicial sobre los DEE. Si, en general, los jueces deberían respetar los márgenes de discrecionalidad de las autoridades/funcionarios cuyos actos controlan, en particular deberían hacerlo en el caso del DEE: limitarse a verificar si el decreto está firmado por todos los ministros y si la suma de los gastos no excede el $2 \%$ del presupuesto nacional ${ }^{52}$. En esto, el control de los tribunales no debería distinguirse del control practicado por CGR ${ }^{53}$.

Preservar la discrecionalidad del PDR para enfrentar emergencias nacionales al margen de la Ley de Presupuesto es condición que ofrece mejores garantías desde la perspectiva del desempeño institucional: sujetar la prudencia del gobernante a los cánones del control judicial amenaza con desvirtuar tanto la función política como la judicial ${ }^{54}$.

Ante una limitación tan estricta del control judicial sobre los DEE, es razonable preguntarse si en estas condiciones tiene algún sentido practicarlo. Cuestionamiento que se agudiza cuando se observa que el control judicial sería un contencioso-objetivo, que dejaría intacta, por tanto, la responsabilidad del PDR ${ }^{55}$. Sin perjuicio de las razones que podrían defender el control judicial incluso en estas condiciones (por ejemplo, el valor ejemplar de una nulidad ${ }^{56}$ o la eventualidad de impedir algún giro no realizado a

cuyo contenido toca determinar al PDR. Respecto de la relación entre discrecionalidad y conceptos jurídicos indeterminados, Moraga, 2010, pp. 37-39; Cordero, 2007, pp. 165-166; Barros, 2010, p. 509.

${ }^{52}$ Cordero, 2007, pp. 161-165, acerca de la deferencia como una condición indispensable del control judicial.

${ }^{53}$ En este marco es oportuno recordar el artículo 21B de la L. 10.336, introducido por la Ley 19.817 de 2002, que excluye la evaluación del mérito o conveniencia de la decisiones políticas y administrativas del control de legalidad que efectúa CGR. Morales, 2012, p. 213, proyecta el alcance de esta disposición, para concluir, sin lugar a dudas, "que el Órgano Contralor tiene por función ejercer el control de legalidad a los actos administrativos y, en caso alguno, a los actos políticos o de gobierno”. En la discusión acerca del control de CGR sobre el gobierno, la entonces ministra de Justicia, Mónica Madariaga, subrayó la estrecha relación entre la interpretación finalista de la ley y la autonomía del Ejecutivo para gobernar, advirtiendo que "el día que otro órgano se atribuya [el poder para ponderar las motivaciones del Presidente de la República, ese día] entra a gobernar”, CENC, sesión 319a.

54 Yowell, 2018, pp. 90-96, advierte sobre la proyección de los límites intrínsecos a la función judicial en el diseño de los tribunales de justicia: no están institucionalmente capacitados para lidiar con el razonamiento político.

55 Estimamos que la disposición contenida en el artículo 38 inciso $2^{\circ}$ de la Constitución ("sin perjuicio de las responsabilidades que pudieren afectar al funcionario que hubiere causado el daño") no vale para el PDR, porque prima lo dispuesto por el artículo $53 \mathrm{~N}^{\circ} 1$ inciso $5^{\circ}$ : el PDR debe haber sido declarado culpable por el Senado. Solo privado de su investidura podría ser juzgado por un tribunal de justicia.

${ }^{56}$ Debemos esta idea al profesor Gabriel Bocksang. Aquí resulta oportuno preguntarse por el control del DEE por medio de la acción de nulidad de derecho público (NDP). La respuesta dependerá de la amplitud que se le reconozca a dicha acción, que es una cuestión controvertida. A la luz de su formulación canónica, Sото KLOSs, 1996, pp. 173-209, el DEE sería susceptible de control sin restricciones. Sin embargo, la jurisprudencia ha venido limitando significativamente el alcance de la NDP, BERMúdEZ, 2010, pp. 114-122, dando con ello pie para pensar que la acción intentada contra el DEE tendría remotas posibilidades de ser acogida. Especial fuerza nos hace aquí, para dudar de la eficacia de la NDP, el peso que la jurisprudencia le ha reconocido a la ilegalidad, en sentido estricto, como factor decisivo en la configuración del supuesto de hecho de la acción, Bermúdez, 2010, pp. 120-122; factor que se vuelve crítico en la casación en el fondo, donde la Corte Suprema ha entendido la causal "infracción de ley" en sentido literal. Por todas, Corte Suprema, 14.11.2012, rol 2033-2010. 
la fecha de la sentencia), nos inclinamos por negarle al Poder Judicial competencia para controlar los DEE. Son varias las razones que nos mueven a ello.

En primer lugar, nos parece que resulta más consistente con la naturaleza eminentemente política (gubernativa, si se prefiere) de la potestad del PDR y con la consiguiente irresponsabilidad judicial del PDR en el ejercicio de dicha potestad. En efecto, la posibilidad de sancionar judicialmente con la nulidad un DEE obscurece la trayectoria política que recorre el acto desde su motivación hasta su finalidad, insinuando en cambio que se trataría de un acto administrativo que se correspondería con una potestad administrativa.

En segundo lugar, tanto el acto como la potestad que le da origen están sujetos a otros mecanismos de control, lo que permite abrirse a la posibilidad de que el diseño institucional haya excluido el control judicial desde su origen. El DEE es controlado por CGR (artículo 99); puede ser controlado por la Cámara de Diputados mediante su poder de fiscalización (artículo $51 \mathrm{~N}^{\circ} 1$ letra a) o, de manera indirecta, por ambas cámaras mediante la acusación constitucional (artículos $52 \mathrm{~N}^{\circ}$ s 2 y $53 \mathrm{~N}^{\circ} 1$ ); finalmente, puede ser controlado por el TC cuando es requerido por un cierto número de parlamentarios (artículo $\left.93 \mathrm{~N}^{\mathrm{o}} 16\right)^{57}$.

Tercero, el riesgo de que la actividad de control judicial se expanda hacia los elementos discrecionales del DEE. Este riesgo de expansión indebida, que es intrínseco al ejercicio de cualquier potestad, significaría en este caso que los jueces vendrían como a sustituir al titular del poder de gobierno en el ejercicio de la prudencia política. Cuestión que, además de representar una amenaza para el buen gobierno (los jueces son jueces, no gobernantes), puede ser visto como un desconocimiento impropio de la legitimidad democrática del PDR ${ }^{58}$.

Por último, la existencia de actos del Poder Ejecutivo marginados de la competencia judicial no le es ajena a nuestros tribunales. Sea bajo la categoría de los actos de gobierno o no, hay sentencias que le reconocen al Ejecutivo un espacio de actuación que está libre del control judicial ${ }^{59}$. Acoger la tesis de la inimpugnabilidad judicial de los DEE no debería causar escándalo entre los jueces.

57 Viene a complementar esta lectura la limitación de la competencia de los tribunales de justicia a los asuntos civiles y criminales solamente, es decir, con exclusión de los actos del gobierno, Bravo, 1996, p. 99, que se hace patente -entre otros ejemplos- en el artículo $4^{\circ}$ del Código Orgánico de Tribunales, BARRIENTOS, 1992, p. 128.

${ }^{58}$ Asimismo, es notorio el impulso expansivo que desde la Corte Suprema amplía su competencia en desmedro de la competencia de los órganos políticos. Dos sentencias ejemplares son, Corte Suprema, 18. 11. 2015, rol 17393 y Corte Suprema, 6. 11. 2018, rol 17043 rol 17393.

59 Por ejemplo, Corte Suprema, 28.5.2009, rol 6585-2007; Corte Suprema, 9.4.2012, rol 16283; Corte Suprema, 18.10.2007, rol 3975-2007 (prevención del Ministro Pierry); Corte Suprema, 16.1.2006, rol No 2377-2005; Corte Suprema, 24.12.2013, rol 4029-2013; Corte Suprema, 12.8.2014, rol 6143-2014; Corte Suprema, 12.8.2014, rol 2839-2014. 


\section{CONTROL POLÍtico y SUPREMACÍA CONSTITUCIONAL}

La inmunidad judicial del DEE no significa que el PDR esté por sobre la Constitución ni que sea un Poder superior al Judicial. El DEE es objeto de control jurídico por parte de CGR y del TC, y de control político por parte de la Cámara de Diputados. En estas instancias se prueba que tanto el DEE como el PDR están sujetos a la Constitución.

Correspondiéndose con la naturaleza esencialmente política de la potestad del artículo $32 \mathrm{~N}^{\circ} 20$, la articulación del control de su ejercicio reconoce a la política un lugar primordial. Así, en el caso de dar curso al DEE, CGR debe remitir automáticamente los antecedentes a la Cámara de Diputados. Si CGR se negara a dar curso al DEE porque excede el $2 \%$ del presupuesto de la nación, deberá también remitir los antecedentes a la Cámara de Diputados (artículo 99). ¿Por qué? Porque se trata de un problema político. Es conveniente recordar que el DEE fue un mecanismo creado para limitar el crecimiento del gasto público vía decretos de insistencia, y que el contexto de su creación fue una reforma constitucional dirigida a restringir las atribuciones del Congreso en materia de gasto público, traspasando la iniciativa de varias materias con ello relacionadas al PDR. En definitiva, el arreglo constitucional que resultó vino a reforzar el diseño de la Constitución de 1925, en que el PDR tenía la iniciativa en materia de gasto público y su ingreso era por medio de la Cámara de Diputados (artículo 45 incisos $2^{\circ}$ y $3^{\circ}$ ). La regla del artículo 99 de la Constitución que estamos discutiendo reproduce la lógica que subyace al artículo 65 incisos $2^{\circ}$ al $5^{\circ}$, que regula el proceso político para decidir cómo gastar los recursos públicos. En otras palabras, esta disposición reconoce que, más allá de la verificación de las formalidades legales, CGR debe traspasar la discusión respecto del gasto público - un asunto político- a su sede natural, el Congreso Nacional; la Cámara de Diputados, específicamente ${ }^{60}$.

Es racional plantearse aquí la posibilidad de que el PDR, disconforme con el razonamiento que ha llevado a CGR a concluir que el DEE excede el límite constitucional del gasto, decida someter la controversia al arbitrio del TC (artículo 99 inciso $3^{\circ}$ ). En este caso, aunque el control del TC sea jurídico, la decisión que habilita su intervención descansa completamente en el PDR, quien naturalmente ponderará el asunto según criterios políticos.

El control practicado por el TC en virtud del artículo $93 \mathrm{~N}^{\circ} 16$ tiene también un elemento político que es determinante: el TC solo puede controlar el DEE a requerimiento de un grupo de parlamentarios. Naturalmente, la decisión de requerir obedecerá a criterios políticos. La dimensión política de este control viene a ser reforzada por los elementos políticos inherentes a la integración y funcionamiento del TC, así como por la deferencia que la jurisprudencia del TC ha observado respecto de la autonomía propia de los órganos políticos ${ }^{61}$.

\footnotetext{
60 Ver nota 29.

${ }^{61}$ Peredo, 2018, pp. 212-226.
} 
A lo dicho debemos agregar que las decisiones de CGR en esta materia no estarían sujetas a revisión judicial ${ }^{62}$. Lo mismo cabría afirmar respecto de las actuaciones de las cámaras del Congreso ${ }^{63}$. Por último, no lo están las decisiones del TC, por expresa disposición constitucional (artículo 94 inciso $1^{\circ}$ ).

\section{CONCLUSIÓN}

El DEE representa uno de esos espacios de autonomía del poder político respecto del control judicial. La naturaleza del objeto propio del DEE (necesidades impostergables derivadas de circunstancias graves y urgentes de bien común) exige que sea atendido por el Poder Ejecutivo en el despliegue de su función gubernativa, autorizando un ejercicio amplio de prudencia política. Es así como el texto constitucional adquiere eficacia: mediante un acto eminentemente político. Como cualquier forma de expresión de una potestad pública, este acto está sujeto a control. Pero el control es eminentemente político, acorde con la naturaleza del acto: es el Congreso quien puede juzgar si, más allá de las formalidades, la decisión del Ejecutivo se ajustó a la Constitución. La consecuencia que de esto se sigue es que la garantía del principio de supremacía constitucional, en este punto al menos, está entregada al poder político. En un contexto más amplio, esto significa que la defensa de la Constitución no es una responsabilidad monopolizada por el poder jurisdiccional, sino compartida con el poder político. De todo ello puede inferirse que la Constitución tiene una dimensión política que es garantizada por un poder de la misma naturaleza.

\section{BIBLIOGRAFÍA}

Aguilar, Mario, 2005: Acto de gobierno. Valoración Jurídico-política, México: Editorial Porrúa Aristóteles, Nicomachean Ethics, H. Rackham, Ed. Disponible en http://data.perseus.org/texts/ urn:cts:greekLit:tlg0086.tlg010.perseus-eng1.

Argandoña, Manuel, 1981: "Reflexiones sobre la potestad reglamentaria y su control jurídico en el anteproyecto de Constitución, X Jornadas de Derecho Público", pp. 193-225.

Aquino, Tomás de, Sententia libri Ethicorum, Editio Leonina. Disponible en http://www.corpusthomisticum.org/

Aquino, Tomás de, Summa Theologiae, Editio Leonina. Disponible en http://www.corpusthomisticum.org/

Aylwin, Patricio y Azócar, Eduardo, 1996: Manual de Derecho Administrativo, Chile: Universidad Nacional Andrés Bello.

${ }^{62}$ Por todos, CGR, de 17.10.2000, N 39570; y la decisión del Senado que acogió la tesis de CGR en el conflicto con la Corte Suprema acerca del órgano competente para definir el régimen previsional del personal de la DGAC, Sesión 87 ${ }^{\mathrm{a}}$, Ordinaria, 6 de marzo de 2018.

63 Silva, 2017, pp. 231 y ss.; Bulnes, 1989, p. 202. En contra, Sото Kloss, 2009, pp. 619-623 (ver también nota 47). 
Bulnes, Luz, 1989: "El recurso de protección y las atribuciones exclusivas del Senado y de la Cámara de Diputados", Revista chilena de derecho, volumen.16, No 2, pp. 199-205.

Barros, Enrique, 2010: Tratado de responsabilidad extracontractual, Chile: Editorial Jurídica de Chile. Bravo, Bernardino, 1996: Por la razón o la fuerza. El Estado de Derecho en la Historia de Chile, Chile: Ediciones Universidad Católica de Chile.

BARrientos, Javier, 1992: "La fiscalización de los actos de gobierno en la época indiana y su desaparición durante la república”, Revista de Estudios Históricos y Jurídicos, número 15, pp. $105-130$.

Bermúdez, Jorge, 2010: "Estado actual del control de legalidad de los actos administrativos. ¿Qué queda de la Nulidad de Derecho Público?”, Revista de Derecho, Valdivia, Vol. XXIII, pp. 103-123.

Blackstone, William, 1794: Commentaries on the Laws of England, 12th edition, Dublin: L. White, William Jones and John Rice.

Bordalí, Andrés, 2002: Temas de Derecho Procesal Constitucional, Universidad Austral de Chile y Editorial Fallos del Mes.

Caldera, Hugo, 1991: "Función de gobierno y función administrativa", Revista de Derecho Público, volumen 49, pp. 205-215.

Cazor, Kamel y Pfeffer, Emilio, 2009: "La búsqueda de criterios orientadores en la configuración de las potestades normativas en Chile", Revista Ius et Praxis, volumen 15, número 1, pp. 191-227.

CEA, José Luis, 2000: Teoría del Gobierno, Chile: Ediciones Universidad Católica de Chile.

CEA, José Luis, 2012: Derecho Constitucional Chileno, Tomo III, $2^{a}$ edición, Chile: Ediciones Universidad Católica de Chile.

Cordero, Luis, 2007: El control de la administración del Estado, Chile: LexisNexis.

Edwards, Alberto, 1928: "La fronda aristocrática", Chile: Imprenta Nacional. Disponible en http://www.memoriachilena.cl/archivos2/pdfs/mc0007410.pdf

García, Gonzalo y Contreras, Pablo, 2014: Diccionario Constitucional Chileno (coord. Victoria Martínez), Cuadernos del Tribunal Constitucional, número 55. Disponible en: https://www. diccionarioconstitucional.com

Harriet, Fernando, 1963: Historia constitucional de Chile: Las instituciones políticas y sociales (3a edición), Chile: Editorial Jurídica de Chile.

Molina, Hernán, 1981: "Los actos de gobierno y su control”, XV Jornadas de Derecho Público, Chile: Edeval.

Molina, Hernán, 2000: "Los decretos con fuerza de ley en la Constitución”, Revista de Derecho, Universidad de Concepción, número 208, p. 113-126.

Molina, Hernán, 2001a: "Los Decretos con Fuerza de Ley en la Constitución de 1980", Revista Ius et Praxis, volumen 7, número 2, pp. 87-103.

Molina, Hernán, 2001b: Los decretos con fuerza de ley en la Constitución de 1980, en Revista de Derecho, Universidad Católica de Valparaíso, XXII, pp. 421-435.

Molina, Hernán, 2009: Derecho Constitucional, Chile: LegalPublishing.

Moraga, Claudio, 2010: Tratado de Derecho Administrativo, Tomo VII, Chile: AbeledoPerrot/ LegalPublishing.

Morales, Baltazar, 2012: "El mérito, la oportunidad y conveniencia en la Contraloría General de la República”, Contraloría General de la República, 85 años de vida institucional (19272012), pp. 207-220.

MuÑoz, Manuel, 2017: "El control de mérito frente a las auditorías "3e" de la Contraloría General de la República”, Revista Derecho Público Iberoamericano, volumen 10, pp. 129-160. 
Pallavicini, Julio, 2010: "Control de constitucionalidad de la Contraloría General de la República”, Revista de Derecho Público, número 72, pp. 108-132.

Pineda, Rodrigo, 2000: "Las potestades constitucionales del gobierno y el Congreso Nacional en materia de gasto público”, Revista Chilena de Derecho, volumen 27, número 2, pp. 373-395.

Peredo, Marcela, 2018: El margen de apreciación del legislador y el test de margen proporcionado. Ley versus Tribunal Constitucional, Chile: ThomsonReuters.

Silva, Alejandro, 2000: Tratado de Derecho Constitucional, tomo V, Chile: Editorial Jurídica de Chile.

Silva, Luis Alejandro, 2017: “Acusación constitucional y garantía política de la supremacía constitucional”, Revista Ius Et Praxis, volumen 23, número 2, pp. 213-250.

Silva, Luis Alejandro, 2018: "El control judicial de los estados de excepción constitucional: la supremacía del Presidente de la República”, Revista Chilena de Derecho, volumen 45, número 1 , pp. 81-103.

Soto KLoss, Eduardo, 1982: El Recurso de Protección. Orígenes, Doctrina y Jurisprudencia, Chile: Editorial Jurídica de Chile.

Soтo Kloss, Eduardo, 1988: "Acerca del llamado control de mérito de los actos administrativos", Revista de Derecho Público, número 43/44, pp. 117-130.

Soтo Kloss, Eduardo, 1996: Derecho Administrativo, Tomo II, Chile: Editorial Jurídica de Chile.

Sото Kloss, Eduardo, 2009: Derecho Administrativo. Temas Fundamentales, Chile: LegalPublishing/ AbeledoPerrot.

Vivanco, Ángela, 2014: Curso de Derecho Constitucional, Tomo III, Chile: Ediciones Universidad Católica de Chile.

Verdugo, M., Pfeffer, E., Nogueira., H., 2002: Derecho Constitucional, Tomo II, Chile: Editorial Jurídica de Chile.

Verdugo, Mario y García, Ana María, 1998: Manual de Derecho Político, $4^{a}$ edición, Chile: Editorial Jurídica de Chile.

Yowell, Paul, 2018: Constitutional Rights and Constitutional Design: Moral and Empirical Reasoning in Judicial Review, London: Hart Publishing.

ZúÑIga, Francisco, 2001: "Controles de la Potestad Legal y Reglamentaria”, Revista Ius et Praxis, volumen 7 , número 2 , pp. 105-178.

ZúÑIga, Francisco, 2006: "Responsabilidad Constitucional del Gobierno”, Revista Ius et Praxis, volumen 12 , nñumero 2 , pp. 43-74.

\section{Normas Jurídicas citadas}

Constitución Política de la República, publicada con fecha 11 de marzo de 1981.

LEY 10.336, de organización y atribuciones de la Contraloría General de la República, publicada con fecha 25 de mayo de 1952.

LEY 19.817, que modifica la ley orgánica de Contraloría General de la República, publicada con fecha 26 de julio de 2002.

LEY 19.880, Establece bases de los procedimientos administrativos que rigen los actos de los órganos de la Administración del Estado, publicada con fecha 29 de mayo de 2003.

LEy 20.050, Reforma Constitucional que introduce modificaciones a la Constitución Política de la República, publicada con fecha 26 de agosto de 2005.

\section{Jurisprudencia citada}

Tribunal Constitucional, sentencia de fecha 26 de abril de 1997, rol 254.

Corte Suprema, sentencia de fecha 16 de enero de 2006, rol 2377-2005. 
Corte Suprema, sentencia de fecha 18 de octubre de 2007, rol 3975-2007.

Corte Suprema, sentencia de fecha 28 de mayo de 2009, rol 6585-2007.

Corte Suprema, sentencia de fecha 14 de noviembre de 2012, rol 2033-2010.

Conte Suprema, sentencia de fecha 24 de diciembre de 2013, rol 4029-2013.

Corte Suprema, sentencia de fecha 12 de agosto de 2014, rol 2839-2014.

Corte Suprema, sentencia de fecha 12 de agosto de 2014, rol 6143-2014.

Corte Suprema, sentencia de fecha 18 de noviembre de 2016, rol 17043.

Corte Suprema, sentencia de fecha 6 de noviembre de 2018, rol 17393.

Corte de Apelaciones de Santiago, sentencia de fecha 9 de abril de 2012, rol 16283.

Contraloría General de la República, dictamen de fecha 8 de agosto de 1952, N³0.692.

Contraloría General de la República, dictamen de fecha 17 de octubre de 2000, No 39.570.

Contraloría General de la República, dictamen de fecha 1 de agosto de 2006, Nº 35.617.

\section{Otras fuentes}

Actas de la Comisión de Estudios de la Nueva Constitución.

Diario de Sesiones, Senado.

Diario de Sesiones, Cámara de Diputados. 
